\title{
Synthesis and Evaluation of 4-Benzophenone Methoxyl Methacrylate As a Polymerizable Photoinitiator
}

\author{
By Guangyu HoU, ${ }^{1}$ Suqing SHI, ${ }^{2}$ Shiji LIU, ${ }^{1}$ and Jun NIE ${ }^{1, *}$
}

\begin{abstract}
Synthesized 4-benzophenone methoxyl methacrylate (BMM) was used as a polymerizable photoinitiator in combination with 2-(N,N-dimethylamino) ethylmethacrylate (DMEM) to initiate the UV photopolymerization of the mixture of $70 \mathrm{wt} \% 2,2-$ bis[4-(2-hydroxy-3-methacryloxypropoxy)phenyl]-propane (Bis-GMA) and $30 \mathrm{wt} \%$ triethylene glycol dimethylacrylate (TEGDMA). Real time infrared spectroscopy (RTIR) was used to monitor the extent of polymerization and dynamic mechanical analyzer (DMA) was used to measure the mechanical properties of the cured samples. Water sorption and solubility of cured samples were tested according to ISO4049's standards. The obtained results indicated that increasing the concentration of DMEM or BMM led to the increase of double bond conversion and the rate of polymerization. Comparing with the non-polymerizable photoinitiating system in the same curing condition, benzophenone(BP)/ethyl 4-dimethylaminobenzoate (EDMAB), BMM/DMEM showed the slightly higher initiating reactivity. The glass transition temperature $\left(T_{\mathrm{g}}\right)$, storage modulus, water sorption and solubility of the cured samples initiated by BMM/DMEM were slightly lower than that of samples initiated by BP/EDMAB.
\end{abstract}

KEY WORDS: Polymerizable Photoinitiator / FT-IR / Kinetics / Photopolymerization /

The technology of photoinduced polymerizations is widely used in several industrial fields. Important advantages offered by this technology such as high curing speed, reduced release of volatiles compounds because of no solvents, low cost of equipment, good mechanical properties, inertness to solvents and resistance to abrasion of the obtained polymer could be achieved through a high degree of cross-linking reaction. ${ }^{1-6}$

The photoinitiator system is a key component in the formulation, which is capable of absorbing the incident UV and/or visible radiation wavelengths to produce reactive species, then convert the monomer or prepolymer system into a linear or highly crosslinked network. ${ }^{3,4}$ In recent years, the studies were focused on the development of polymeric and polymerizable photoinitiators with reactive functionalities, which could led to higher activity or greater curing speed coupled with lower migration rates and/or water solubility. ${ }^{7-9}$

The free radical photopolymerizations are usually performed in presence of photoinitiators of "cleavage" type (type I) or hydrogen abstraction type (type II). ${ }^{3,4,10}$ The latter was generally used in dental restorative, contact lens, foodpackaging materials, and so on. Benzophenone derivatives as one of the most commonly used photoinitiator could initiate the polymerization of vinyl monomers with an amine as a coinitiator to speed up the reaction. ${ }^{11,12}$ However, the free radical generated by the benzophenone moiety and synergistic amine may actually cause some problems for biomedical or food packaging materials. Some evidence of carcinogenic activity of benzophenone was found by feeding a goups of 50 males and 50 females F344 rats and B6C 3 mice with diets containing $0,312,625$ and $1520 \mathrm{ppm}$ benzophenone for 105 weeks. ${ }^{13}$ Thus, if both the photoinitiator and the synergist could be incorporated into a polymer, the biocompatibility of the polymer would be greatly improved..$^{9,14-17}$

In this study, the mixture of benzophenone-containing methacrylate and a polymerizable amine is expected to have more biocompatibility because it should be incorporated into the final polymer. ${ }^{14,15}$ Real time infrared spectroscopy (RTIR) was used to monitor the extent of polymerization, and dynamic mechanical analyzer (DMA) was used to measure the glass transition temperature $\left(T_{\mathrm{g}}\right)$ and modulus of the resin system. Water sorption and solubility were measured according to ISO 4049's standards.

\section{MATERIALS AND METHODS}

\section{Materials}

2,2-Bis[4-(2-hydroxy-3-methacryloxyprop-1-oxy) phenyl]propane (Bis-GMA, Sartomer), triethylene glycol dimethacrylate (TEGDMA, Sartomer), 2-( $N, N$-diamino)ethyl methacrylate (DMEM, AcrÖs Organics), benzophenone (BP, AcrÖs Organics), and ethyl 4-(dimethylamino)benzoate (EDMAB, Aldrich) were used as received. Other chemicals were analytical reagent and used without further purification. Chemical structures of monomers and photoinitiator system were shown in Figure 1.

\footnotetext{
Methods

NMR. ${ }^{1} \mathrm{H}$ NMR spectra were recorded on a Bruker AV600 unity spectrometer operated at $600 \mathrm{MHz}$, with $\mathrm{CDCl}_{3}$ as solvent.
}

\footnotetext{
${ }^{1}$ Key Lab. of Beijing City on Preparation and Processing of Novel Polymer Materials, College of Material Science and Engineering, Beijing University of Chemical Technology, Beijing, 100029, P. R. China

${ }^{2}$ Department of Chemistry, Northwest University, Xi'an, 710069, P. R. China

*To whom correspondence should be addressed (Tel: +86-10-64421310, Fax: +86-01064421310, E-mail: niejun@mail.buct.edu.cn).
} 
<smiles>C=C(C)C(=O)OCC(O)COc1ccc(C(C)(C)c2ccc(OCC(O)COC(=O)C(=C)C)cc2)cc1</smiles><smiles>C=C(C)C(=O)OCCOCCOCCOC(=O)C(=C)C</smiles><smiles>C=C(C)C(=O)OCc1ccc(C(=O)c2ccccc2)cc1</smiles><smiles>C=C(C)C(=O)OCCN(C)C</smiles><smiles>O=C(c1ccccc1)c1ccccc1</smiles>

$\mathrm{BP}$

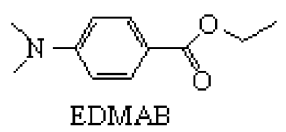

Figure 1. Chemical structure of monomers and photoinitiator system.

FT-IR. The mixture of monomer and photoinitiator was placed in a mold made from glass slides and spacers with $8 \pm 0.5 \mathrm{~mm}$ in diameter and $1.2 \pm 0.1 \mathrm{~mm}$ in thickness. The samples were irradiated by UV spot light source (EFOS Lite, with 320-390 nm filter and $5 \mathrm{~mm}$ crystal optical fiber, Canada) at room temperature with various light intensities (UV Light Radiometer, Beijing Normal University, China). FT-IR (Nicolet 5700, Thermo Electron, USA) was used to monitor absorbance change of $=\mathrm{C}-\mathrm{H}$ peak area from 6107 to $6227 \mathrm{~cm}^{-1}$ in the near IR range which was correlated to the extent of polymerization. For each sample, the series FT-IR runs were repeated three times.

DMA. A dynamic mechanical analyzer (DMA) (Rheometyic, USA) was used to measure the mechanical properties. The samples were photocured at room temperature with a UV light source (EFOS Lite, 320-390 nm filter, light intensity $=20$ $\mathrm{mW} / \mathrm{cm}^{2}$ ) for $15 \mathrm{~min}$ in a mold made from glass slides and spacers. The polymerized samples were put at room temperature for $5 \mathrm{~d}$ after curing to ensure that postpolymerization process was complete. The samples used for DMA were thin rectangular films of $1.2 \mathrm{~mm}$ thickness and dimensions of $7 \mathrm{~mm} \times 35 \mathrm{~mm}$. Dynamic mechanical analysis was performed over a temperature range from -50 to $200{ }^{\circ} \mathrm{C}$ with a ramping rate of $5^{\circ} \mathrm{C}$ per minute using extension mode. The loss and storage modulus and the loss tangent $(\tan \delta$, ratio of loss to storage modulus) were recorded as a function of temperature, and the glass transition temperature $\left(T_{\mathrm{g}}\right)$ was taken to be the maximum of the loss tangent versus temperature curve.

Water Sorption and Solubility. Water sorption and solubility were measured according to ISO 4049's standards. The specimens, $15 \pm 1 \mathrm{~mm}$ in diameter and $1.2 \pm 0.1 \mathrm{~mm}$ in thickness, were stored in a desiccator that contained anhydrous calcium chloride. The samples were maintained at $37 \pm 1{ }^{\circ} \mathrm{C}$ for $24 \mathrm{~h}$. The temperature was then decreased to $23^{\circ} \mathrm{C}$ for $1 \mathrm{~h}$ and the samples were subsequently weighed to an accuracy of $\pm 0.2 \mathrm{mg}$. This process was repeated until a constant mass $\mathrm{m}_{1}$ was obtained. The specimens were then immersed in water and maintained at $37^{\circ} \mathrm{C}$ for $7 \mathrm{~d}$. After this time, the samples were taken out, washed with water, blotted to remove surface water, waved in air for $15 \mathrm{~s}$, and weighed 1 min after removal from water. This measurement was recorded as $\mathrm{m}_{2}$. Following this weighing, the specimens were replaced into the desiccator, and the cycle described previously was repeated until a final constant mass was obtained $\left(\mathrm{m}_{3}\right)$. For each polymer system, the value taken was the average of five specimens. The specimen volumes (V) were also measured. To calculate the water sorption $\left(\mathrm{W}_{\mathrm{sp}}\right)$ and solubility $\left(\mathrm{W}_{\mathrm{sl}}\right)$, the following equations were used:

$$
\begin{aligned}
& \mathrm{W}_{\mathrm{sp}}=\left(\mathrm{m}_{2}-\mathrm{m}_{3}\right) / \mathrm{V} \\
& \mathrm{W}_{\mathrm{sl}}=\left(\mathrm{m}_{1}-\mathrm{m}_{3}\right) / \mathrm{V}
\end{aligned}
$$

All samples were cured with a UV light source (EFOS Lite, $320-390 \mathrm{~nm}$, light intensity $=20 \mathrm{~mW} / \mathrm{cm}^{2}$ ) for 10 minutes before measurement.

Synthesis of BMM. BMM was synthesized by the following procedure (Figure 2). A mixture of $0.0691 \mathrm{~mol}(14.61 \mathrm{~g}$ ) of 4-(hydroxymethyl)benzophenone (HBP), $0.076 \mathrm{~mol}$ (7.86 g) of triethylamine and $150 \mathrm{~mL}$ of toluene was added into a three-necked flask, equipped with stirrer, thermometer, dropping funnel. Under ice-water bath cooling $\left(0-5^{\circ} \mathrm{C}\right), 0.076 \mathrm{~mol}$ $(7.96 \mathrm{~g})$ of methacryloyl chloride dissolved in $10 \mathrm{~mL}$ of toluene was added during $4 \mathrm{~h}$. Then, the mixture was allowed to stand overnight. The precipitate was filtered off. The organic phase was washed with $100 \mathrm{~mL}$ of $1 \mathrm{~mol} / \mathrm{L} \mathrm{HCl}, 100 \mathrm{~mL}$ of $1 \mathrm{~mol} / \mathrm{L}$ $\mathrm{NaHCO}_{3}$, and $150 \mathrm{~mL}$ of water for three times. The organic phase was dried overnight with $\mathrm{Na}_{2} \mathrm{SO}_{4}$. Subsequently, the organic phase was evaporated under vacuum to remove the solvent. The slight yellow crude product was purified by column chromatography (silica gel 200-300 mash) using ethyl acetate/hexane $2 / 1(\mathrm{wt} / \mathrm{wt})$ as elution to give the colorless liquid product. The yield was $4.53 \mathrm{~g}(56 \%)$. The final product was identified with FT-IR and ${ }^{1} \mathrm{H}$ NMR.

FT-IR 2957, $2928 \mathrm{~cm}^{-1}(\mathrm{CH}), 1720 \mathrm{~cm}^{-1}(\mathrm{C}=\mathrm{O}), 1637$ $\mathrm{cm}^{-1}(\mathrm{C}=\mathrm{C}), 816 \mathrm{~cm}^{-1}$ (=C-H). ${ }^{1} \mathrm{H}-\mathrm{NMR}\left(\mathrm{CDCl}_{3}, \delta\right) 1.99$ $\left(-\mathrm{CH}_{3}, 3 \mathrm{H}\right), 5.28\left(-\mathrm{CH}_{2}-\mathrm{OC}(=\mathrm{O}), 2 \mathrm{H}\right), 5.63,6.20\left(=\mathrm{CH}_{2}, 2 \mathrm{H}\right)$, 7.26-7.82 (-benzene, 9H).

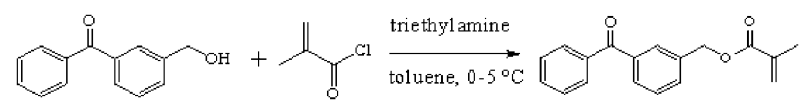

Figure 2. Synthesis process of BMM. 

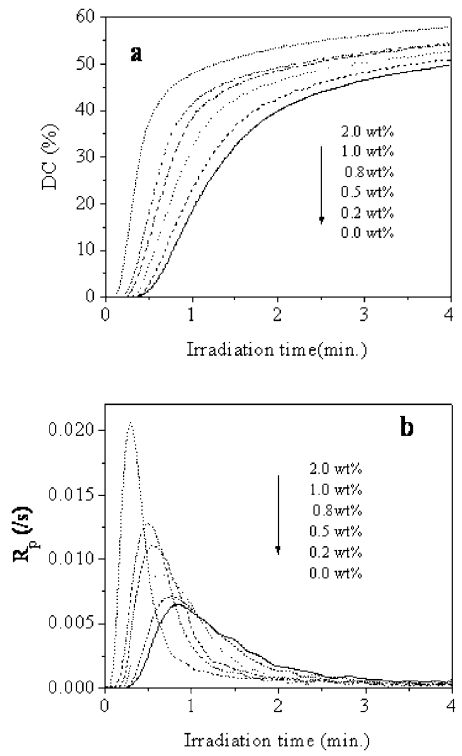

Figure 3. Effect of [DMEM] on DC and $R_{p}$ of Bis-GMA/TEGDMA (70/30 wt $\%),[B M M]=1.0 \mathrm{wt} \%, \mathrm{I}=20 \mathrm{~mW} / \mathrm{cm}^{2}$.

\section{RESULTS AND DISCUSSION}

\section{Photopolymerization Kinetics}

The real-time IR (RTIR) technology has been widely used to measure the double bond conversion of (meth)acrylate monomers under irradiation. ${ }^{18,19}$ The decrease of the $=\mathrm{C}-\mathrm{H}$ near IR absorption peak area from 6107 to $6227 \mathrm{~cm}^{-1}$ accurately reflects the extent of polymerization. The rate of polymerization $\left(R_{p}\right)$ could be calculated by the time derivative of the double bond conversion (DC).

In this study, a Bis-GMA/TEGDMA (70/30 wt \%) was photopolymerized as resin mixture with various BMM/DMEM photoinitiator system. Figure 3 was the kinetics of Bis-GMA/ TEGDMA at constant [BMM] $(1.0 \mathrm{wt} \%)$ and different [DMEM] $(0,0.2,0.5,0.8,1.0$ and $2.0 \mathrm{wt} \%)$. Increasing the concentration of DMEM ([DMEM]) led to the increase of both DC and the rate of polymerization. When the [DMEM] was increased from 0 to $2.0 \mathrm{wt} \%$, the final double conversion for $4 \mathrm{~min}$ exposure increased from $46 \%$ to $58 \%$ and the rate of polymerization increased as well. This was because higher coinitiator concentration yielded more radicals, thus led to the higher polymerization rate and DC. On the other hand, this might be due to the free volume effect, which was caused by the volume shrinkage. ${ }^{20}$ The volume shrinkage occurred at very fast rate of polymerization and resulted in an increase of freevolume formation which increased the mobility of the residual double-bond and led to a higher double bond conversion. The induction period was shortened with the increase of [DMEM] at the same time, because photopolymerization carried out in the presence of air, the initiating radicals were scavenged by oxygen molecules dissolved in the formulation. When the oxygen was consumed, the monomer molecules become capable of successfully reacting with the initiator radicals,
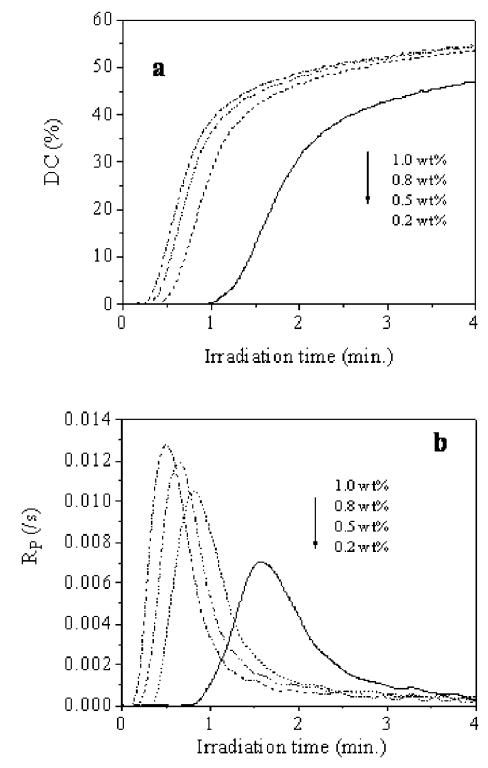

Figure 4. Effect of $[B M M]$ on $D C$ and $R_{p}$ of Bis-GMA/TEGDMA (70/30 wt \%), $[D M E M]=1.0 \mathrm{wt} \%, \mathrm{I}=20 \mathrm{~mW} / \mathrm{cm}^{2}$.

thus initiating polymerization. Increase [DMEM] could produce large amounts of free radicals rapidly to overcome oxygen inhibition.

The kinetics of Bis-GMA/TEGDMA at the same [DMEM] concentration (1.0 wt \%) and different [BMM] $(0.2,0.5,0.8$, and $1.0 \mathrm{wt} \%$ ) were shown in Figure 4 . When the concentration of BMM was increased from $0.2 \mathrm{wt} \%$ to $0.5 \mathrm{wt} \%$, the the final double conversion for $4 \mathrm{~min}$ exposure increased from about $45 \%$ to $55 \%$, and the rate of polymerization was greatly increased from $0.007 \mathrm{~s}^{-1}$ to $0.011 \mathrm{~s}^{-1}$. The induction period was greatly shortened as well. However, continuing increasing [BMM] only caused the slight increase of final double bond conversion and the rate of polymerizaiton. This was because at the higher initiator concentration the initiating efficiency of the initiator system was greatly affected by the light screening of the initiator itself and its photolysis products.

Figure 5 showed the kinetics of Bis-GMA/TEGDMA initiatied by $0.5 \mathrm{wt} \% \mathrm{BMM}$ and $1.0 \mathrm{wt} \%$ DMEM] with different UV light intensity. It was observed that increasing the UV light intensity increased both the double bond conversion and the rate of polymerization. When the UV light intensity was increased from 5 to $40 \mathrm{~mW} / \mathrm{cm}^{2}$, the final double conversion for $4 \mathrm{~min}$ exposure increased from $20 \%$ to $58 \%$ and the maximum rate of polymerization increased from $0.002 \mathrm{~s}^{-1}$ to $0.011 \mathrm{~s}^{-1}$. This was because the higher light intensity could yield more radicals which led to the increase in polymerization rate and final double bond conversion. At the same time, the more radicals yielded by the increase of light intensity could overcome oxygen inhibition more efficiently, resulting in the shortening of the induction period.

Figure 6 was the comparison of kinetics of Bis-GMA/ TEGDMA $(70 / 30 \mathrm{wt} \%)$ initiated by BMM/DMEM $(0.5 /$ $1.0 \mathrm{wt} \%)$ and $\mathrm{BP} / \operatorname{EDMAB}(0.5 / 1.0 \mathrm{wt} \%)$. It was observed that $\mathrm{BMM} / \mathrm{DMEM}$ and $\mathrm{BP} / \mathrm{EDMAB}$ could reach the same DC 

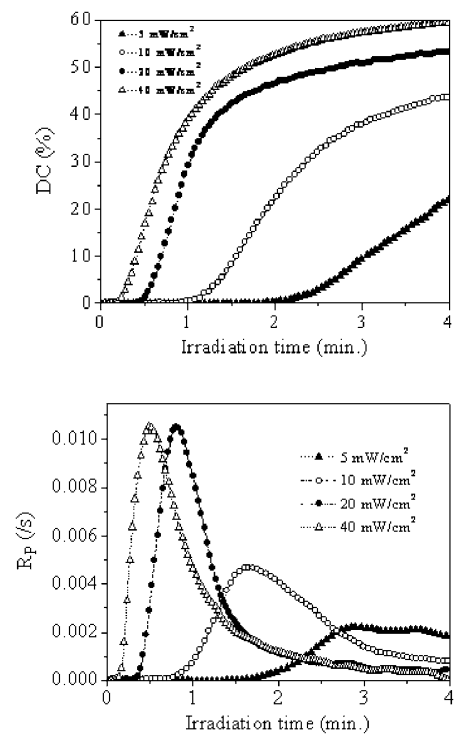

Figure 5. The effect of light intensity on the kinetics of Bis-GMA/TEGDMA $(70 / 30 w t \%)[B M M]=0.5 w t \%,[D M E M]=1.0 w t \%$.
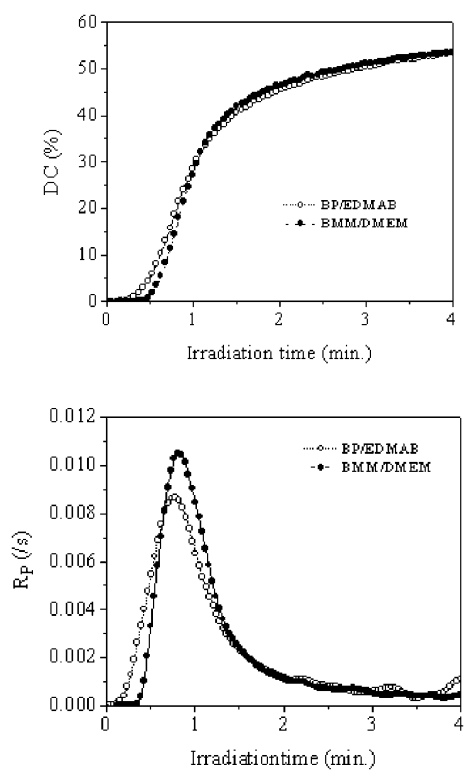

Figure 6. Comparison of BMM/DMEM (0.5/1.0 wt \%) with BP/EDMAB (0.5/ $1.0 \mathrm{wt} \%)$ for the Bis-GMA/TEGDMA $(70 / 30 \mathrm{wt} \%), \mathrm{I}=20 \mathrm{~mW} / \mathrm{cm}^{2}$.

(55\%). But the former led to slightly higher maximum $R_{p}$, which meant that the reactivity of $\mathrm{BMM} / \mathrm{DMEM}$ was relatively higher than that of $\mathrm{BP} / \mathrm{EDMAB}$ in the same curing condition.

\section{DMA Characteristics}

The DMA results for two different resin mixtures were shown in Figure 7. The storage modulus of Bis-GMA/ TEGDMA/BMM/DMEM sample was slightly lower than that of Bis-GMA/TEGDMA/BP/EDMAB sample. The glass transition temperatures $\left(T_{\mathrm{g}}\right)$ of the Bis-GMA/TEGDMA/BMM/ DMEM was $75^{\circ} \mathrm{C}$, also lower than that of Bis-GMA/ TEGDMA/BP/EDMAB $\left(86^{\circ} \mathrm{C}\right)$. This might relate to the
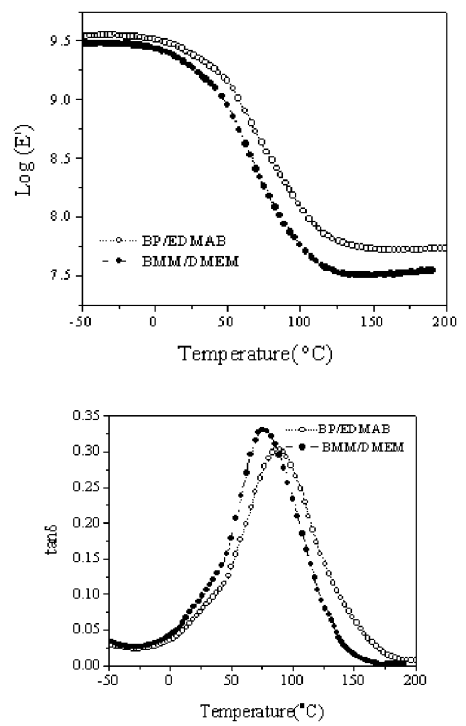

Figure 7. Storage modulus and glass transition temperature of Bis-GMA/ TEGDMA/BMM $(0.5 \mathrm{wt} \%) / \mathrm{DMEM}(1.0 \mathrm{wt} \%)$ and Bis-GMA/ TEGDMA/BP(0.5 wt \%)/EDMAB(1.0wt \%).

Table I. Water sorption and solubility of Bis-GMA/TEGDMA/BMM(0.5 wt \%)/ $\operatorname{DMEM}(1.0 \mathrm{wt} \%)$ and Bis-GMA/TEGDMA/BP(0.5 wt \%)/EDMAB(1.0 wt \%), average of five samples \pm Standard Deviation $\left(\mu \mathrm{g} / \mathrm{mm}^{3}\right)$

\begin{tabular}{lcc}
\hline & Water sorption & Solubility \\
\hline Bis-GMA/TEGDMA/BMM(0.5 wt \%)/ & $27.33 \pm 0.48$ & $2.55 \pm 0.07$ \\
$\begin{array}{l}\text { DMEM(1.0 wt \%) } \\
\text { Bis-GMA/TEGDMA/BP }(0.5 \text { wt } \%) /\end{array}$ & $28.85 \pm 0.56$ & $2.86 \pm 0.06$ \\
EDMAB $(1.0$ wt $\%)$ & &
\end{tabular}

network formation. For Bis-GMA/TEGDMA/BMM/DMEM, copolymerization of BMM and dimethacrylate monomer system led to relatively lower mobility of the free radical reactive species. It might cause the relatively looser network and lead to the lower $T_{\mathrm{g}}$.

\section{Water Sorption and Solubility}

Table I gave the results of water sorption and solubility of Bis-GMA/TEGDMA/BMM(0.5 wt \%)/DMEM(1.0 wt \%) and Bis-GMA/TEGDMA/BP (0.5 wt \%)/EDMAB(1.0 wt \%). The results indicated that the water sorption and solubility of BMM system was slightly lower than BP system. It might be due to the incorporation of BMM and/or DMEM moiety into the polymer chain. The incorporation of the predominant part of a benzophenone-based photoinitiator and tertiary amine coinitiator into the polymer chain reduced the possibility of their diffusion from the resin into water or other surrounding solution. Thus, a considerably lower toxicity of the resulting resins than that of resins cured with nonpolymerizable low molecular weight initiator system could be expected.

\section{CONCLUSIONS}

BMM could be synthesized by common method as a polymerizable photoinitiator. Increasing the concentration of BMM or DMEM could lead to the increase of double bond 
conversion and rate of polymerization. Compared with the nonpolymerizable initiator system(BP/EDMAB), BMM/ DMEM reached the same final double bond conversion $(55 \%)$ for $4 \mathrm{~min}$ exposure but relatively higher rate of polymerization. Although the glass transition temperature and the storage modulus of BMM/DMEM system were slightly lower than that of BP/EDMAB system, the lower water sorption and solubility for BMM/DMEM system make it more biocompatibility and more promising in the application such as biomaterials and food package.

Received: April 15, 2007

Accepted: November 30, 2007

Published: January 29, 2008

\section{REFERENCES}

1. S. P. Pappas, "UV Curing: Science and Technology," Technology Marketing Corporation, Stamford, Wiley, New York, 1992.

2. R. Holman and P. Oldring, "SITA books for UV and EB Chemistry," Sita, London, 1990.

3. J. P. Fouassier and J. F. Rabek, "Radiation Curing in Polymer Science and Technology," Chapman \& Hall, London, 1993.

4. J. P. Fouassier, "Photoinitiation, Photopolymerization, Photocuring," Hanser, Munich, 1995
5. H. Y. He, L. Li, and L. J. Lee, Polymer, 47, 1612 (2006).

6. S. H. Zhang, B. Li, L. M. Tang, X. G. Wang, D. S. Liu, and Q. X. Zhou, Polymer, 42, 7575 (2001).

7. F. Catalina, C. Peinado, and N. S. Allen, J. Photochem. Photobiol. A Chem., 67, 255 (1992).

8. A. Ajayaghosh, Polymer, 36, 2049 (1995).

9. T. Corrales, F. Catalina, C. Peinado, and N. S. Allen, J. Photochem. Photobiol. A Chem., 159, 103 (2003).

10. H. F. Gruber, Prog. Polym. Sci., 17, 953 (1992).

11. J. F. Rabek, "Mechanisms of Photophysical Processes and Photochemical Reaction in Polymers," Wiley, New York, 1987.

12. T. B. Cavitt, B. Phillips, C. E. Hoyle, B. Pan, S. B. Hait, K. Viswanathan, and S. J. Jonsson, J. Polym. Sci., Part A: Polym. Chem. 42, 4009 (2004).

13. M. C. Rhodes, J. R. Bucher, J. C. Peckham, G. E. Kissling, M. R. Hejtmancik, and R. S. Chhabra, Food Chem. Texicol., 45, 843 (2007).

14. F. S. Du, P. Zhang, and F. M. Li, J. Appl. Polym. Sci., 51, 2139 (1994).

15. J. Wang and L. J. Mathias, Polym. Int., 54, 1537 (2005).

16. B. Vazquez, C. Elvira, B. Levenfeld, B. Pascual, I. Coni, M. Gurruchaga, M. P. Ginebra, F. X. Gil, J. A. Planell, P. A. Liso, M. Rebuelta, and J. S. Roman, J. Biomed. Mater. Res., 34, 129 (1997).

17. J. Nie and C. N. Bowman, Biomaterials, 23, 1221 (2002).

18. J. W. Stansbury and S. H. Dickens, Dent. Mater., 17, 71 (2001).

19. P. Kerbouc'h, P. Lebaudy, P. Lecamp, and C. Bunel, Thermochim Acta, 410, 73 (2004).

20. J. G. Kloosterboer, G. M. M. Van de Hei, R. G. Gossink, and G. C. M. Dortant, Polym. Commun., 25, 322 (1984). 